\title{
Improved conflict resolution in romantic couples in mediation compared to negotiation
}

\author{
François Bogacz (10) 1,2,3凶 , Thierry Pun ${ }^{1,2} \&$ Olga M. Klimecki $i^{1,4,5,6 凶}$
}

Despite the frequency and adverse effects of conflict, randomized controlled studies on interventions that could promote conflict resolution (e.g., among romantic couples) are scarce. One understudied intervention technique is mediation, which is a negotiation facilitated by a neutral third party. To test the impact of a mediator on couple conflict, we conducted a randomized controlled study involving 38 romantic couples who discussed a topic of recurrent disagreement either in the presence of a mediator or by means of a direct negotiation. The results show that romantic couples in the mediation condition, compared with those in direct negotiation, had a probability of reaching an agreement 1.39 times higher and reported higher satisfaction regarding the content and process of their discussions. In addition, the synchronicity of the couple's skin conductance, a measure of arousal, correlated with the couple's closeness and with the quality of their relationship. Our findings suggest that interventions based on mediation can have a beneficial impact on conflict resolution.

\footnotetext{
${ }^{1}$ Swiss Centre for Affective Sciences, University of Geneva, Chemin des Mines 9, 1202 Geneva, Switzerland. ${ }^{2}$ Computer Vision and Multimedia Laboratory, University of Geneva, Battelle Campus, Building A-7, route de Drize, 1227 Carouge, Switzerland. ${ }^{3}$ Melbourne Business School, 200 Leicester St, Carlton, VIC 3053, Australia. ${ }^{4}$ Laboratory for the Study of Emotion Elicitation and Expression, Department of Psychology, University of Geneva, Boulevard du Pont d'Arve 40, 1205 Geneva, Switzerland. ${ }^{5}$ Laboratory for Behavioral Neurology and Imaging of Cognition, Department of Neuroscience, Medical School, University of Geneva, rue Michel Servet 1, 1211 Geneva, Switzerland. ${ }^{6}$ Clinical Psychology and Behavioral Neuroscience, Faculty of Psychology, Technische Universität

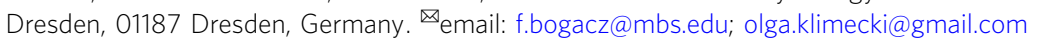


s couple conflicts have a negative impact on health and divorce rates (Haddad et al., 2016), it is important to identify interventions that can help to resolve these conflicts. This randomized controlled study tested how mediation, a form of third-party intervention, impacts on couple conflicts. To this end, self-report data were complemented by psychophysiological measures of the linkage in electrodermal activity between couple members. In addition, the present study explored the relation of personality traits such as mindfulness, emotional competence, and conflict behaviours to conflict outcomes in order to expand previous findings on these relations (Barnes et al., 2007; Mueller and Curhan, 2006; Davis et al., 2004, respectively).

When not properly managed, interpersonal conflicts can take a severe toll on the disputants directly or indirectly involved, for instance in the case of couple conflicts (Haddad et al., 2016). In fact, divorce rates have risen in both industrialized and nonindustrial countries in the last century (Marriage and divorce statistics, 2019), affecting the health and well-being of individuals and causing strains on relationships not only within the couple, but within families and social communities (Coontz, 2006). Furthermore, research has shown that, even if recurring marital conflicts did not lead to divorce, marital strain accelerated the decline in health in a representative sample of adults (Umberson et al., 2006) and that, for men and women with the lowest levels of marital quality, exiting marriage through divorce or separation brought a lower risk of depression than remaining married did (Williams, 2003). In spite of the research on conflict dynamics within romantic couples ("couple conflicts") (Gottman and Levenson, 1992; Driver and Gottman, 2004; Bloch et al., 2014; Shaw, 2014), there is so far a lack of randomized controlled studies on third-party interventions that may promote conflict resolution. Negotiation, which can be defined as a 'formal discussion between people who have different aims or intentions, [...] during which they try to reach an agreement' (Collins English Dictionary, 2020) or as 'the joint decision making between interdependent individuals with divergent interests' (Pruitt, 1998) is the default strategy adopted by parties involved in most conflicts, including couples. However, negative emotions often disturb the process of direct negotiations (Van Kleef et al., 2004, 2006; Van Kleef and Côté, 2007; Pietroni et al., 2008; Lelieveld et al., 2012), in particular in couple conflicts (Retzinger and Scheff, 2000).

Possible interventions consist of training people to help them improve their emotional self-management skills (e.g., with conflict coaching, Brinkert, 2011; self-distancing, Kross and Ayduk, 2008; or reappraisal, Finkel et al., 2013). A particularly promising technique that has been studied in the context of couple conflict is emotional reappraisal training. A randomized controlled study on the impact of emotional reappraisal training, for instance, showed that regular 7-min reappraisal exercises about disagreements over several months preserved self-reported marital quality (Finkel et al., 2013).

In addition to training people in using certain self-management techniques, the involvement of third parties, such as a marital therapist or couple counsellor in cases of couple conflicts has yielded positive effects on family interactions and behaviours (Lebow et al., 2012). Indeed, it has been shown that couple therapy positively impacted $70 \%$ of couples receiving treatment (Lebow et al., 2012). In particular, cognitive-behavioural marital therapy was shown to induce significant change in spouses' posttherapy relationship-related cognitions and behaviours (Dunn and Schwebel, 1995). However, research has also found that $30 \%$ of couples who recovered thanks to therapy had relapsed after 2 years, and that 4 years after treatment, $38 \%$ of couples had divorced (Williams, 2003). Gottman also estimated that 'only
$11-18 \%$ of couples maintained clinically meaningful initial gains when treated with our best marital therapies' (Gottman, 1999, p. 5). Furthermore, self-management training, conflict coaching, marital therapy, and counselling approaches have so far not been widely adopted by societies and communities. Research conducted in the state of Oklahoma in the United States, for instance, found that only $37 \%$ of divorced couples had sought counselling before getting a divorce and only 19\% of married couples had sought counselling for their current marriage (Stanley et al., 2001). Conflicts in couples are thus prone to relapse and escalation, and parties often end up using legal proceedings to solve them. An alternative to therapy or counselling that has not been rigorously studied to date is mediation.

Mediation, which is 'a negotiation facilitated by a neutral thirdparty' (International Mediation Institute, 2020b), has emerged in the last 30 years as an alternative to legal proceedings. The role of the mediator can be '... to help those involved sort out their issues and arrive at a consensus. That might involve helping parties to finalize an agreement, resolve a dispute, develop effective communications, build or improve relationships, or all these things. Mediators do not take sides. Mediators are impartial' (International Mediation Institute, 2020b). Mediation is thus a fluid and "ad hoc" practice and mediators can adopt and combine many styles during their interventions, such as facilitative, evaluative, or transformative styles (International Mediation Institute, 2020a). When using a facilitative mediation style, the mediator uses specific processes and techniques to help parties reach an agreement but does not make any formal recommendation to them, in contrast to the evaluative style (International Mediation Institute, 2020a). Transformative mediation has the objective of going beyond resolving a conflict to transforming the parties by empowering them and facilitating mutual recognition of needs, interests, perspectives, values, and emotions (Bush and Folger, 1984).

Previous research has shown that mediation costs generally much less than litigation and is quicker and more effective. For instance, one study of 343 cases in Canada showed that the average savings of mediation compared with litigation was around $\$ 3500$ per case, with more than $\$ 10,000$ in savings for $45 \%$ of cases (Hann et al., 2001). In the same study, only 3\% of 3068 cases needed more than one session of a few hours to be resolved (Hann et al., 2001). A report of the European Parliament (European Parliament, 2011) also found that the average cost to litigate in the European Union was $€ 10,449$, whereas the average cost to mediate was $€ 2497$.

However, to date, when mediation is not compulsory (for instance when using court-annexed schemes), its adoption is still variable. Taking a country where mediation is rather mature and well-researched such as Australia as an example, use of mediation varies greatly depending on the type of case. On the one hand, the 2006 family law reform led to an increase in family dispute cases referred to as the "Family Dispute Resolution" mediation services of the Family Relationship Services Programme, from 14,500 to 22,500 yearly cases in the 4-year period after the reform (Sourdin, 2020). As there are no statistics about the total number of family disputes in the country, this number can be compared with the total number of divorces. With around 50,000 divorces per year, this means that roughly one-third of cases are referred to a sort of mediation. On the other hand, at the state level, for instance in the Victorian Civil and Administrative Tribunal, only 3\% of the 85,191 total cases lodged in 2017-2018 were listed for mediation or 'compulsory conference'; here the resolution rate was $55 \%$ (Victorian Civil and Administrative Tribunal, Annual Report 2017-2018, 2018).

There may be several reasons for the relatively variable use of mediation. The first might be that when the conflict at hand has 
escalated (Glasl, 2013), each party sees the other as the enemy against whom they can fight only with the help of a lawyer, in a tribunal. The second reason might be that empirical data are lacking on how mediation impacts the parties and helps them resolve conflicts. One recent and extensive review of 47 studies on the effectiveness of mediation techniques by a task force of the American Bar Association (Wissler, 2017) could not include a single randomized controlled study and highlighted (Wissler, 2017, p. 12) that 'the complex, interactive, and iterative nature of the mediation process makes it difficult to systematically control how a mediator action is performed, isolate the effect of a particular action from that of other actions, and control for selection and other potentially confounding processes that operate throughout mediation'. The review also concluded that common terminology, definitions, and measures for mediator actions and outcomes would provide more consistency in research. Studies on the effects of mediation have indeed mostly been carried out by comparison to legal proceedings (Brett and Barsness, 1996; Barough et al., 2013; Shaw, 2014) without a proper control group (Kaiser and Gabler, 2014), using role play instead of real conflicts (Jameson et al., 2009) or focusing on the impact of the mediator's techniques on the settlement rate by studying or observing mediation cases (Wissler, 2017). A randomized controlled study is thus needed to establish the causal impacts of a mediator on conflicts. Couple conflicts, where high emotions are often experienced, are an ideal domain to conduct this research.

A consensus is emerging in the mediation community that one of the key mediation techniques is helping parties manage their negative emotions (Jones and Bodtker, 2001; Katz, 2007; Jameson et al., 2009; Swaab and Brett, 2012; Wissler, 2017) since, as mentioned earlier, negative emotions can be detrimental to the outcomes of a negotiation. It is hard to find a unique definition of the effectiveness of mediation and thus of the outcome variables, but several studies (Jones and Bodtker, 1999; Jameson et al., 2009; Finkel et al., 2013; Kaiser and Gabler, 2014; Shaw, 2014; Charkoudian, 2016) point towards the following potential metrics that could be measured at the end of a mediation session: the existence or not of an agreement between parties about what was discussed, the satisfaction of the parties with the session, their perceived level of conflict, their level of positive affect and negative affect, and their perceived interpersonal closeness.

From preliminary evidence of studies on couple conflicts (Levenson and Gottman, 1983, 1985; Driver and Gottman, 2004) and mediation (Jones and Bodtker, 1999; Jameson et al., 2009; Finkel et al., 2013; Kaiser and Gabler, 2014; Shaw, 2014), we hypothesized that, compared with direct negotiation between couple members, mediation should (i) reduce the level of conflict at the end of the discussion as a sign that the couple has moved towards a possible resolution, (ii) increase the satisfaction of the parties regarding the contents of their discussion and the process used in their discussion (Jones and Bodtker, 1999; Shaw, 2014), (iii) increase the positive affect and decrease the negative affect of the parties (Jameson et al., 2009; Shaw, 2014), and (iv) increase interpersonal closeness, which serves as a proxy for couple satisfaction (Finkel et al., 2013).

The impact of mediation on positive and negative affects is of high importance. Recent reviews show that the relation between emotions and conflict resolution is receiving increasing attention in the context of intractable conflicts (Retzinger and Scheff, 2000; Halperin and Gross, 2011; Halperin, 2013, 2015; Halperin et al., 2013), interpersonal and intergroup conflicts (Klimecki, 2019), and organizational conflicts (Nair, 2008). However, few randomized controlled studies have been performed on the impact of interventions on emotions and conflict resolution, which is true in particular for mediation.
As self-report (i.e., questionnaire) measures are prone to social desirability (Crowne and Marlowe, 1960), they can be complemented by biological and thus more implicit measures. One way of quantifying biological measures of affective states, which has been used in studies on interpersonal interactions (Levenson and Gottman, 1983, 1985; Levenson and Ruef, 1992; Chanel et al., 2013) but not in studies on conflict resolution and mediation, is affective computing. Affective computing refers to the study and development of systems and devices that can recognize, interpret, process, and simulate human affects. It is based on the recording and processing of various signals (such as electrodermal activity, cardiovascular activity, facial expressions, speech, or language) that are indicative of affective states (for instance arousal). A question currently debated in affective computing is whether the linkage between the arousal states of two persons, as measured by electrodermal activity synchrony only or by synchrony between various physiological measures, is predictive of positive or negative outcomes in conflictual discussions. On the one hand, some studies suggested that electrodermal activity synchrony between participants who had no relationship prior to the experiment (quantified by Pearson correlations) was predictive of constructive behaviours in a context where participants had to collaboratively design a slogan by brainstorming, debating, and then negotiating ideas (Chanel et al., 2013). Furthermore, electrodermal activity synchrony during a discussion on a topic chosen by friends (quantified by Pearson correlations between the change in slopes) was correlated to emotional engagement behaviours as observed from video recordings, for instance active listening or attending to the other person's emotions (Slovák et al., 2014). Such physiological linkage could be an indicator of empathic processes (Levenson and Ruef, 1992; Guastello et al., 2006). As empathy has been shown to promote prosocial behaviour (Klimecki, 2019), physiological linkage could be a sign of a positive and constructive social interaction. Therefore, one could expect physiological linkage to be linked to more successful discussions and one may expect mediation to increase physiological linkage. On the other hand, physiological linkage has also been related to lower marital satisfaction. More specifically, physiological linkage of romantic couples during a 15-min conflictual discussion (as quantified by an index that combined skin conductance level, heart rate, pulse transmission time to the finger, and measurement of general movement) was negatively related to marital satisfaction (Levenson and Gottman, 1983). Moreover, the relation between the physiological linkage index and marital satisfaction was more pronounced in high-conflict situations as opposed to low-conflict situations (Levenson and Gottman, 1983). Other research found that higher physiological linkage during a conflictual discussion (as quantified by the physiological linkage index mentioned earlier; Levenson and Gottman, 1983) was related to lower self-reports of marital satisfaction in the 3 years following the experiment (Levenson and Gottman, 1985). As emotional and therefore physiological linkage may also be related to empathic distress, which is defined as being emotionally overwhelmed by the other's suffering (Hoffman, 2008) and which has been associated with less prosocial behaviour in the past (Klimecki, 2015), it might be that there are two different emotional mechanisms of physiological linkage at play. Other potential explanations for the seeming discrepant findings on whether physiological linkage is related to better or worse interpersonal relations may stem from (i) the different uses of physiological linkage indices (Pearson correlations or Pearson correlation between the change in the slopes), (ii) the difference in settings (strangers engaged in a collaborative game vs. friends or couples), and (iii) the differences in acquired variables (skin conductance vs. skin conductance level plus heart rate, pulse transmission time to the finger, and general movement). In 
summary, since there is so far no consensus on the role of synchrony between electrodermal activity signals in conflicts, more research is needed to shed light on this topic.

In addition to physiological coupling, it has been suggested that certain personality traits may predict the outcomes of conflict discussion in romantic couples. One such trait is mindfulness, which refers to 'paying attention to the present moment in a nonjudgmental way' (Kabat-Zinn, 2009). Research has shown that higher traits of mindfulness predicted lower levels of negative affect after a conflictual discussion between romantic couple members (Barnes et al., 2007). Another study has shown that mindfulness significantly helped participants to release negative emotions instead of dwelling on them (Brown et al., 2012). Participation in an 8-week mindfulness training programme also increased the support of conciliatory policies in intractable conflicts when compared with that in a waiting-list control group (Alkoby et al., 2017). Moreover, it has been found that emotional intelligence (EI), which is defined as a set of skills that contributes to the understanding and regulation of one's own and others' emotions (Salovey and Mayer, 1990), positively predicted outcome satisfaction in negotiations (Mueller and Curhan, 2006) and that people who rated themselves high in EI also self-reported that they used collaborative solutions more often (Jordan and Troth, 2002). This result is complemented by the finding from couple studies that perceiving one's partner as having higher EI and not avoiding discussing a relationship problem is linked to higher relationship satisfaction (Smith et al., 2008). In addition, couples in which both partners are low on EI tend to have high conflict and low relationship quality (Brackett et al., 2005). Finally, it has not yet been established whether self-reports on preferred conflict behaviours, including constructive behaviours (such as perspective-taking or reaching out) and destructive behaviours (such as expressing anger or retaliating), which are popular in organizational conflict prevention and leadership development (Killman and Thomas, 1977; Capobianco et al., 2008), can predict the outcomes of couple conflict.

In summary, to test the causal influence of a mediator on couple conflict, we randomly allocated heterosexual romantic couples to a mediated discussion or a non-mediated discussion in the presence of a silent third party. To assess the impact of the mediation on (i) conflict management, (ii) couple's emotions, and (iii) the relation between couple members, we assessed the following outcome variables: agreements reached, level of disagreement at the end of the discussion, satisfaction with the contents of the discussion, satisfaction with the process of the discussion, interpersonal closeness, positive and negative emotions, and physiological coupling between the couple members. We also assessed the mediator's satisfaction with the contents and process and explored whether these variables were related to participants' satisfaction. We hypothesized that (i) mediation would have a positive impact on agreements reached, level of disagreement at the end of the discussion, satisfaction with the contents of the discussion, satisfaction with the process of the discussion, interpersonal closeness, and positive and negative emotions; (ii) mindfulness, EI, and the tendency to use constructive behaviours in conflictual discussions would have a positive influence on the outcome variables listed above; and (iii) the tendency to use destructive behaviours would have a negative influence on the outcome variables listed above. We also hypothesized that the higher the parties' satisfaction at the end of the discussion, the higher the mediator's satisfaction would be as a sign of a positive dynamic of the conversation between the mediator and the couple members. Considering that there is no consensus on the role of synchrony between electrodermal activity in conflicts, this study aimed at testing whether physiological linkage as measured by skin conductance synchrony would be positively or negatively related to outcomes of a conflict discussion and how mediation would affect this measure.

\section{Methods}

Participants. Participants were recruited through the distribution of flyers in the city (train station, markets, etc.) and on the various university campuses, as well as through posters displayed on campuses, advertising on Facebook and Instagram, and word of mouth from friends. Participants were told that they were participating in a study about communication within couples 'to examine the factors that influence discussions on topics of disagreement among couples'. Among the participants who contacted us, $74 \%$ did so in response to posters; $12 \%$ in response to flyers; $9 \%$ in response to word of mouth from friends, family, or colleagues; and $5 \%$ in response to advertising on social networks. Nineteen heterosexual romantic couples (mean age $=28.18$ years) participated in the control condition and 19 heterosexual romantic couples (mean age $=30.61$ years) participated in the mediation condition. This sample size was above the minimum size of 25 dyads recommended by Kenny and colleagues for dyadic studies (Kenny et al., 2006). Volunteers were included if they had been in a romantic relationship for more than 1 year, if they spoke French or English fluently, and if they were at least 18 years old. The average level of disagreement across the 15 possible topics from the Dyadic Adjustment Scale was 3.75 for our participants (from 0 , meaning always disagree, to 5 , meaning always agree), with 3 meaning occasionally disagree and 4 meaning frequently agree. The sum scores of the 32 items of the Dyadic Adjustment Scale for our participants had a mean of 113.6 versus a mean of 114.8 for 218 married couples and 70.7 for 94 divorced couples in the original paper that presented the Dyadic Adjustment Scale instrument (Spanier, 1976), suggesting that our sample was representative of married couples. An independent $t$ test revealed no difference between Dyadic Adjustment Scale scores of participants in the mediation condition $($ mean $=114.53)$ and those of participants in the control group $($ mean $=112.74)$ $(t=-0.43, p=0.67)$. Couples were randomly assigned to one of the two conditions (mediation or control condition in the presence of a silent third party), and the two groups were matched for age and length of relationship. As shown in Supplementary Table 1 , independent sample $t$-tests revealed that the participants in both groups, in addition to age and the length of relationship, did not differ on any of the pre-conflict intervention independent variables (all $t \leq 0.98$ and all $p \geq 0.33$ ). These variables included Dyadic Adjustment Scale, mindfulness, emotional competence, and Conflict Dynamics Profile (CDP) scores (see "Measures" section for details on the questionnaires). The mediators (seven in total, four females and three males) were members of the same professional mediation association (the Swiss Chamber of Commercial Mediation, Section Romande) and were selected on the basis of their common approach to mediation as a facilitative (as opposed to evaluative) practice of conflict resolution (Riskin, 2005). Because of scheduling complexities, the mediators could not be randomly assigned to their sessions but were allocated according to temporal availability.

Measures. For ease of reading, the measures used in this study are presented below in the order in which they were collected. All phases are indicated in italic.

Trait measures collected prior to the conflict discussion: Prior to the experiment (on average, 25 days beforehand), all volunteers had to individually complete four online profiling questionnaires in French or English administered with SurveyMonkey (San Mateo, CA, USA). The objective was to (i) focus their visit to the laboratory on the conflict discussion, (ii) uncouple trait measures 
as much as possible from state measures, (iii) collect in advance the topics of disagreement, and (iv) print a side-by-side comparison of the scoring by both couple members on the possible topics of discussion in order to help them choose the topic for their discussion for which their level of recurring disagreement was the highest. The four trait measures were as follows:

(1) The Dyadic Adjustment Scale (Spanier, 1976), which measures the quality of the relationship and which was used to identify the topic of the discussion during the experiment. This scale uses 32 items grouped into four subscales (Dyadic Consensus, Dyadic Satisfaction, Dyadic Cohesion, and Affectional Expression) and the level of disagreement on 15 recurring topics of discussion (from 1, "always agree", to 6, "always disagree").

(2) The profile of emotional competence (Brasseur et al., 2013), which measures intrapersonal and interpersonal emotional competence (with the five subscales Identification, Expression, Comprehension, Regulation, and Utilization) as a proxy for EI. This measure uses 50 statements for which the answer is indicated on a scale from 1 to 5 , with 1 meaning that the statement does not describe the person at all or that they never respond like this, and 5 meaning that the statement describes the person very well or that they experience this particular response very often.

(3) The five-facet mindfulness questionnaire (Baer et al., 2006), which measures the level of dispositional mindfulness. This questionnaire uses 36 statements for which the answer is indicated on a scale from 1 to, 5 with 1 meaning that the statement is never or very rarely true for the person, and 5 meaning that the statement is very often or always true. The scales are grouped into five types of behaviour: (i) observing/noticing/attending to sensations/perceptions/ thoughts/feelings, (ii) describing/labelling with words, (iii) acting with awareness/non-distraction, (iv) non-judging of experience, and (v) non-reactivity to inner experience.

(4) The CDP (Capobianco et al., 2008), which measures preferences for using four types of responses to conflicts: active-constructive (e.g., perspective-taking), passiveconstructive (e.g., delayed responding), active-destructive (e.g., expressing anger), and passive-destructive (e.g., avoiding conflicts). The CDP uses 63 statements about the way the person usually responds before, during, and after the occurrence of interpersonal conflicts in their life and for which the answer can range from 1 to 5 , with 1 meaning that the person never responds in that way and 5 meaning that the person almost always responds in that way.

State measures collected in the lab prior to the discussion included two questionnaires:

(1) The positive and negative affect schedule (PANAS), a 20item questionnaire that measures the current levels of positive and negative affect of the participant, listing feelings and emotions that the person may feel in the moment on a scale from 1 to 5 , with 1 meaning that the person feels the emotion very slightly or not at all, and 5 meaning that the person feels the emotion extremely (Crawford and Henry, 2004).

(2) The inclusion of other in the self (IOS) scale, which measures the degree of closeness to the other couple member. It asks participants to circle a picture that best describes their relationship among seven pictures made of two circles named "Self" and "Other", with the first picture (no overlapping between the two circles) giving a score of 1 and the last picture (with the two circles almost completely overlapping) giving a score of 7 (Aron et al., 1992).

During the intervention, to obtain an objective measure of emotional arousal, we continuously recorded electrodermal activity by means of two electrodes attached to the palm of participants' non-dominant hand. Participants' heart rate was continuously recorded by means of an optical sensor attached to the index finger of each participant's non-dominant hand. Electrodermal activity and heart rate data were collected with the MP36 Biopac System (Santa Barbara, CA, USA). Because of a high degree of movement artefacts (from 30 to more than 100 per session for some participants), heart rate variability could not be analysed accurately. All discussions were videotaped with Sony HDR-CX455 Digital HD Video Camera Recorders (Tokyo, Japan), with one camera per participant for the discussion (including the mediator, when present).

After the intervention, participants again filled out the PANAS and the IOS Scale, as well as a satisfaction questionnaire to indicate (i) whether they had achieved an agreement on the topic of their discussion (yes or no); (ii) the level of disagreement at the end of their discussion on the topic that was discussed, using an 11-point scale (ranging from 0 to 10); (iii) their level of satisfaction with the contents of their discussion; and (iv) their level of satisfaction with the process used to conduct their discussion. Both satisfaction with the contents and the process were rated by using a continuous scale from 0 , meaning "not at all", to 10 , meaning "extremely", which was converted to values with one decimal point for analysis. More specifically, participants were asked: "To what extent are you satisfied with the content of the discussion in which you participated?" and "To what extent are you satisfied with the process that you used to resolve your disagreement with your partner?"

Procedure. When participants arrived at the laboratory, they filled out the PANAS and the IOS questionnaires. The participants were then invited to select a controversial topic for their discussion based on the highest scores of the 15 topics of recurring disagreement identified with the Dyadic Adjustment Scale questionnaire. The experimenter in the control condition or the mediator in the mediation condition was available to assist participants in choosing their controversial topic if the results of the questionnaire were indecisive. In the control condition, minimal instructions were given by the experimenter prior to the start of the discussion and some general written guidelines were provided to the disputants (see Supplementary Note S1). This information guided the participants in conducting their controversial discussions in a structured way without the couple asking for any support from the experimenter. These participants were left free to decide when they wanted to finish the session. Participants in both conditions could take notes during their controversial discussions. After having distributed the instructions, the experimenter sat in a corner of the room and monitored the data collection while remaining silent and minimizing eye contact with the participants, who were instructed to sit facing each other at a round table. In the mediation condition, the mediator was instructed to sit equidistant from both participants around the same round table and to facilitate a discussion of $\sim 60 \mathrm{~min}$, using a process inspired from a facilitative mediation model known to the mediators (see Supplementary Note S2). As indicated in Supplementary Table 1, the duration of the interactions was balanced across both conditions (with a mean duration of $50 \mathrm{~min}$ in the mediation condition and $55 \mathrm{~min}$ in the control condition). At the end of the discussion, participants were invited to fill out the PANAS and IOS questionnaires again, as well as to answer the satisfaction questionnaire. One couple in the control group who 
got into a very emotional discussion did not fill out the PANAS and satisfaction questionnaires at the end of the discussion, as we interrupted their increasingly heated discussion in order to help them calm down (they were referred to a mediation centre). Furthermore, the IOS values of these couple members from before the discussion were missing. The couple's results were retained in the analysis, except for the results for the IOS Scale, the PANAS, and satisfaction with the discussion, where their data were missing.

The study was carried out in accordance with the Declaration of Helsinki and the study protocol was approved by the ethics committee of the Faculty of Psychology and Science Education at the University of Geneva, Switzerland. All participants provided written informed consent and received monetary compensation of $20 \mathrm{CHF}$ per hour for their participation, as well as a debriefing, in which their individual profiles about their tendency to use active-constructive, passive-constructive, active-destructive, and passive-destructive conflict behaviours were shared with them. The experimenter, a certified mediator himself, helped to reduce any remaining levels of tension between the participants in the control condition at the end of the experiment and was ready to provide the contact information of a mediation centre for further follow-up on the topic of disagreement, should this be needed (which happened only once).

Statistical analysis. Questionnaire data were analysed with IBM SPSS 25 software (Armonk, NY, USA). Pearson and Spearman correlations were used to assess the relation between different baseline questionnaires, as well as relations between baseline questionnaires and outcome variables. Differences in the number of self-reported agreements (binary variable) between the mediation and control group were analysed by using a chi-square test. Regarding interval variables, the dependent variables measured after each conflict discussion were (i) satisfaction with the contents of the discussion, (ii) satisfaction with the process of the discussion, (iii) level of disagreement, (iv) satisfaction of the mediator with the contents of the discussion, and (v) satisfaction of the mediator with the process of the discussion. In addition, the following variables that were dependent on the interval level were measured before and after the conflict discussion: (vi) positive affect, (vii) negative affect, and (viii) interpersonal closeness measured by the IOS. In line with current practices about dyadic data analysis (Kenny et al., 2006; Ditzen et al., 2012), we first analysed the intra-class correlation of outcome variables by using the Pearson correlation between couple members. When there was an independence of data between the couple members (as indicated by a $p$ value of $\geq 0.20$ for the Pearson correlation between the couple members), we analysed the data by using each participant as a unit of analysis in an analysis of variance or a multivariate analysis of variance (MANOVA). When there was non-independence of data (as indicated by a $p$ value of $<0.20$ for the Pearson correlation), an actor-partner interdependence model (APIM) was used to measure the possible impact of mutual influence of couple members on outcome variables, while using the condition as a co-variate. The analysis was done with APIM_SEM (Stas et al., 2018).

To analyse the synchronicity of electrodermal activity data between the members of each couple, we used two previously developed methods, the first index based on the Pearson correlation coefficient between the electrodermal activity time series of dyadic participants (an index referred to as the Pearson correlation) (Chanel et al., 2013) and the second index based on the correlation between the change in the slope of the electrodermal activity signals (referred to as correlation between the change in slopes) (Slovák et al., 2014). Electrodermal activity data were first analysed with Acqknowledge 4.1 (Goleta, CA, USA) and then in MATLAB R2015b (Natick, MA, USA) and IBM SPSS 25 (Armonk, NY, USA).

\section{Results}

Correlations between questionnaires. To test whether mindfulness, emotional competence, active-constructive conflict behaviours, passive-constructive conflict behaviours, passivedestructive conflict behaviours, and active-destructive conflict behaviours were independent between couple members, we conducted Pearson correlations (Alferes and Kenny, 2009) that showed that only active-destructive conflict behaviours were not independent $(p=0.12$, all other $p \geq 0.2$ ).

To test the extent to which mindfulness, emotional competence, active-constructive conflict behaviours, passiveconstructive conflict behaviours, and active-destructive conflict behaviours were interrelated, we conducted Pearson correlations, since those variables were normally distributed. As shown in Supplementary Table 2, mindfulness was positively correlated with active-constructive conflict behaviours $(r=0.23, p=0.005)$ and with passive-constructive conflict behaviours $(r=0.3$, $p=0.001$ ), indicating that more mindful participants had more constructive conflict behaviours. All other correlations were not significant (all other $r \leq 0.19$, all other $p \geq 0.11$ ). To test the extent to which passive-destructive conflict behaviours and the Dyadic Adjustment Scale score were interrelated and related to mindfulness and emotional competence, we used Spearman correlations because those variables were not normally distributed. As depicted in Supplementary Table 3, mindfulness was negatively correlated with passive-destructive conflict behaviours $\left(r_{\mathrm{s}}=\right.$ $-0.32, p=0.005)$ and the Dyadic Adjustment Scale score was positively correlated with the total emotional competence score $\left(r_{\mathrm{s}}=0.30, p=0.008\right)$. In other words, more mindful participants had less passive-destructive conflict behaviours and more emotionally competent participants were more satisfied with their relationship. All other correlations were not significant (all other $r_{\mathrm{s}} \leq 0.015$, all other $p \geq 0.39$ ).

To test whether gender had an impact on mindfulness, emotional competence, dyadic adjustment, and active-constructive, passive-constructive, active-destructive, and passivedestructive conflict behaviours, we conducted independent $t$-tests with gender as a factor and mindfulness, emotional competence, dyadic adjustment, and active-constructive, passive-constructive, active-destructive, and passive-destructive conflict behaviours as dependent variables. These tests revealed that there were no significant differences between gender on all these variables (all $p \geq 0.11$ ).

To test the extent to which age and personality traits (Dyadic Adjustment Scale score, mindfulness, emotional competence, and active-constructive, passive-constructive, active-destructive, and passive-destructive conflict behaviours) were correlated with the outcome variables related to the conflict discussion (change in positive affect, change in negative affect, satisfaction with the contents of the discussion, satisfaction with the process of the discussion, level of disagreement at the end of the discussion, and IOS after the discussion), we conducted Spearman correlations because all outcome variables were not normally distributed. Regarding age, all Spearman correlations were not significant (all $r_{s} \leq 0.09$, all $p \geq 0.45$ ). Regarding personality traits, Spearman correlations revealed that the preference to use activeconstructive conflict behaviours was positively related to satisfaction with the contents of the discussion $\left(r_{s}=0.26\right.$, $p=0.005)$, satisfaction with the process of the discussion $\left(r_{s}=0.27, p=0.018\right)$, and the IOS after the discussion $\left(r_{\mathrm{s}}=0.25\right.$, $p=0.033)$. This result indicated that participants who reported 
using more active-constructive conflict behaviours in general were more satisfied with the content and process of the conflict discussion and reported more closeness with their partner. There was no relation between the preference to use passive-destructive conflict behaviours and the change in negative affect. The observed tendency ( $r=-0.25, p=0.03$ ) was due to five outliers that were more than 2 standard deviations above or below the mean of the change in negative affect. Removing these outliers revealed no significant correlation between passive-destructive conflict behaviours and the change in negative affect $\left(r_{\mathrm{s}}=-0.10\right.$, $p=0.38$ ). The total Dyadic Adjustment Scale score, which measured the quality of the relationship, was negatively correlated with the level of disagreement at the end of the discussion $\left(r_{\mathrm{s}}=\right.$ $-0.26, p=0.026)$ and with the IOS after the discussion $\left(r_{\mathrm{s}}=0.34\right.$, $p=0.003)$.

To test how age, length of relationship, and personality traits were correlated with the IOS before the discussion (a discrete variable), we conducted Spearman correlations. There was no relation between age and the IOS before the discussion. The observed tendency $\left(r_{\mathrm{s}}=-0.25, p=0.027\right)$ was due to four outliers that were more than 2 standard deviations below the mean of the IOS after the discussion. Removing these outliers revealed no significant correlation between age and the IOS before the discussion $\left(r_{\mathrm{s}}=-0.12, p=0.92\right)$. There was a significant positive relation between the Dyadic Adjustment Scale score and the IOS before the discussion $\left(r_{s}=0.34, p=0.004\right)$, indicating that participants with higher adjustment scores reported being closer. There was also a significant negative relation between the active-constructive conflict behaviours and the IOS before the discussion $\left(r_{\mathrm{s}}=0.25, p=0.039\right)$, as well as a significant negative relation between the active-constructive conflict behaviours and the passive-destructive conflict behaviours $\left(r_{\mathrm{s}}=-0.33, p=0.005\right)$. All other correlations were not significant (all other $r_{\mathrm{s}} \leq 0.09$, all other $p \geq 0.45$ ). To test whether gender had an impact on the outcome variables related to the conflict discussion (change in positive affect, change in negative affect, satisfaction with the contents of the discussion, satisfaction with the process of the discussion, IOS after the discussion, and level of disagreement at the end of the discussion), we conducted independent $t$-tests that revealed no significant difference between genders (all $p \geq 0.13$ ).

The impact of mediation on couple conflict. The main aim of this experiment was to test the degree to which mediation can have an impact on couple conflict as indexed by (i) agreements obtained on the topic of discussion, (ii) satisfaction with the contents of the discussion and satisfaction with the process of the discussion, (iii) the level of disagreement at the end of the discussion, (iv) the change in positive affect and the change in negative affect, and (v) the IOS after the discussion.

To assess whether couples in the mediation condition reported more agreement on the topic of their discussion after the discussion (binary outcome variable), we computed a chi-square test. This analysis revealed that couples in the mediation condition reported more agreements than did couples in the control condition $\left(\chi^{2}(1)=8.76, p=0.006\right)$. More specifically, 36 of 38 participants declared that they had reached an agreement in the mediation condition, whereas 26 of 38 participants did so in the control condition. Based on the odds ratio, the probability of reaching an agreement was 1.39 times higher in the mediation condition than in the control condition.

Regarding the outcome variables that were measured on an interval level, the calculation of Pearson correlation coefficients (Alferes and Kenny, 2009) revealed that the change in positive affect and the change in negative affect (all $p \geq 0.20$ ) were
Effect of experimental condition on affective states

4

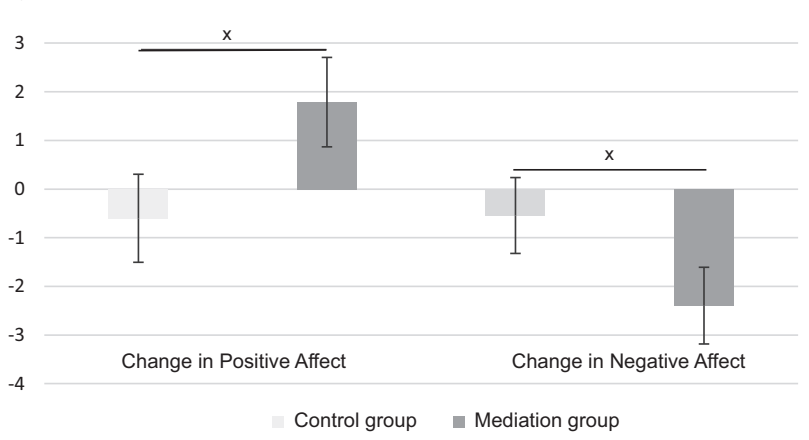

Fig. 1 Compared with the control condition, mediation tended to increase positive affect and to decrease negative affect. Bars depict means and 1 standard error of the mean. ${ }^{x_{p}}<0.1$

Table 1 Means and standard deviations of inclusion of other in the self (IOS) before and after the conflict discussion for the control and mediation conditions (from 1, very far apart, to 7 , very close).

\begin{tabular}{lll} 
Mean & Control & Mediation \\
\hline IOS before & $4.38(S D=1.07)$ & $4.39(S D=1.02)$ \\
IOS after & $4.39(S D=1.20)$ & $4.64(S D=1.10)$ \\
\hline
\end{tabular}

independent between couple members. However, the IOS before and the IOS after the discussion were not independent between couple members ( $p=0.010$ and $p=0.016$, respectively).

We thus conducted a MANOVA with the dependent variables change in positive affect and change in negative affect and the between-group variable condition (mediation and control) to test whether mediation had an impact on the affective state of the participants. This analysis revealed a significant effect of mediation on change in positive affect and change in negative affect $(F(2,71)=3.47, p=0.036)$. As illustrated in Fig. 1, independent $t$-tests revealed that, compared with the control condition, mediation tended to increase positive affect $(t(71)=1.87, \quad p=0.069)$ and to decrease negative affect $(t(71)=1.67, p=0.099)$.

To test whether interpersonal closeness was affected by mediation versus the control condition, as well as by dyadic adjustment scores and active-constructive conflict behaviours, we used an APIM. With the APIM, we examined the effect of one couple member's IOS before the discussion on their own reports of IOS after the discussion (i.e., the actor effect), as well as on the partner's reports on the IOS after the discussion (i.e., the partner effect) (see Table 1 for mean values of the IOS before and after the discussion). The condition was included in the model as a between-dyad covariate and treated as a binary variable. The Dyadic Adjustment Scale and active-constructive conflict behaviours were included in the model as well as between-dyad covariates. There was a significant actor effect both for women $(=0.81, p<0.001,95 \%$ confidence interval $(\mathrm{CI})[0.65,0.98])$ and for men $(=0.81, p<0.001,95 \%$ CI $[0.61,0.01])$. However, the model did not show any partner effect, condition effect, activeconstructive conflict behaviour effect, or Dyadic Adjustment Scale effect (all $p \geq 0.110$ ). Removing four outliers that were more than 2 standard deviations above or below the mean of the IOS before the discussion and the IOS after the discussion did not change the results. As we had hypothesized that mediation would result in more interpersonal closeness, we tested whether there was a significant effect of condition on the IOS. We thus conducted 
pairwise $t$-tests that compared the IOS before and after the discussion in the mediation and control conditions separately. As shown in Table 1, this analysis revealed that the IOS increased from before to after the conflict discussion for the mediation condition $(t(37)=-2.92, p=0.006)$ but did not change in the control condition $(t(35)=-0.94, p=0.35)$. Removing the outliers did not change these results.

Regarding satisfaction with the contents of the discussion, satisfaction with the process of the discussion, and level of disagreement at the end of the discussion, the calculation of Pearson correlation coefficients (Alferes and Kenny, 2009) revealed that these variables were not independent across couple members (all $p \leq 0.05$ ). To test the impact of mediation on these three outcome variables, we thus conducted APIM analyses by using APIM_SEM (Stas et al., 2018). In these models, baseline variables that correlated with the outcome variables after the conflict discussion were used as predictor variables. Activeconstructive conflict behaviour was included as a predictor for satisfaction with the contents of the discussion and satisfaction with the process of the discussion, and the Dyadic Adjustment Scale was included as a predictor for the level of disagreement at the end of the discussion.

First, we tested the impact of mediation and active-constructive conflict behaviours on satisfaction with the contents of the discussion by using APIM (see Fig. 2). More specifically, this model tested the effect of one couple member's activeconstructive conflict behaviours on their own reports of satisfaction with the contents of the discussion (i.e., the actor effect), and on the partner's satisfaction with the contents of the discussion (i.e., the partner effect). Condition (mediation or control) was included in the model as a between-dyad covariate and treated as a binary variable. There was a significant actor effect both for women (equal to $0.063, p=0.045,95 \%$ CI [0, $0.13]$ ) and for men (equal to $0.065, p<0.001,95 \%$ CI $[0.03,0.1]$ ). The overall actor effect was estimated to be $0.064(p<0.001,95 \%$ CI $[0.03,0.1])$. There was a trend in a men-to-women partner effect (equal to $0.05, p=0.078,95 \%$ CI $[-0.01,0.11]$ ) and in a women-to-men partner effect (equal to $-0.041, p=0.051,95 \%$ CI $[-0.08,0])$. Regarding the effect of condition, women in the mediation condition had on average a value on satisfaction with the contents of the discussion that was 1.06 points higher than that of women in the control condition and this difference was statistically significant $(p=0.02)$. Men in the mediation condition had on average a value on satisfaction with the contents of the discussion that was 1.08 points higher than that of men in the control condition. This difference was also statistically significant $(p<0.001)$.

To test the impact of mediation and active-constructive conflict behaviours on satisfaction with the process of the discussion, we used the APIM to examine the effect of one couple member's active-constructive conflict behaviour score on their own reports of satisfaction with the process of the discussion (i.e., the actor effect) and on the partner's satisfaction with the process of the discussion (i.e., the partner effect) (see Fig. 3). Condition

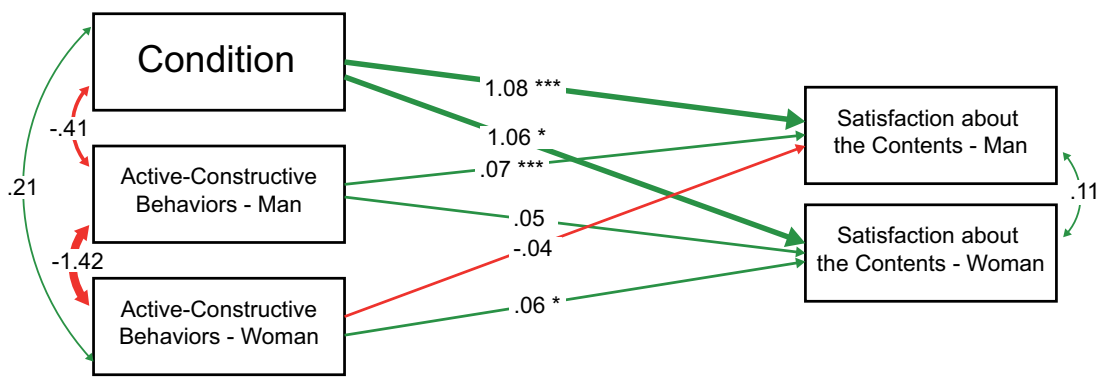

Fig. 2 Full APIM model: Mediation had a significant effect on satisfaction with the contents of the discussion for both genders. Higher reports of participants on active-constructive conflict behaviours were related to higher reports of their own reports of satisfaction with the contents of the discussion. Positive estimates are indicated with green arrows, negative estimates with red arrows. The stronger the effect, the thicker the arrow. The double-headed arrows between "Active-Constructive Man" and "Active-Constructive Woman", "Condition" and "Active-Constructive Man", and "Condition" and "Active-Constructive Woman" represent the covariance of these pairs of variables. The double-headed arrow between "SatisfactionContents Woman" and "Satisfaction-Contents Man" is the residual non-independence in these outcome scores, which is represented by the covariance between their corresponding two error terms. ${ }^{\star * *} p<0.001$ and ${ }^{*} p<0.05$.

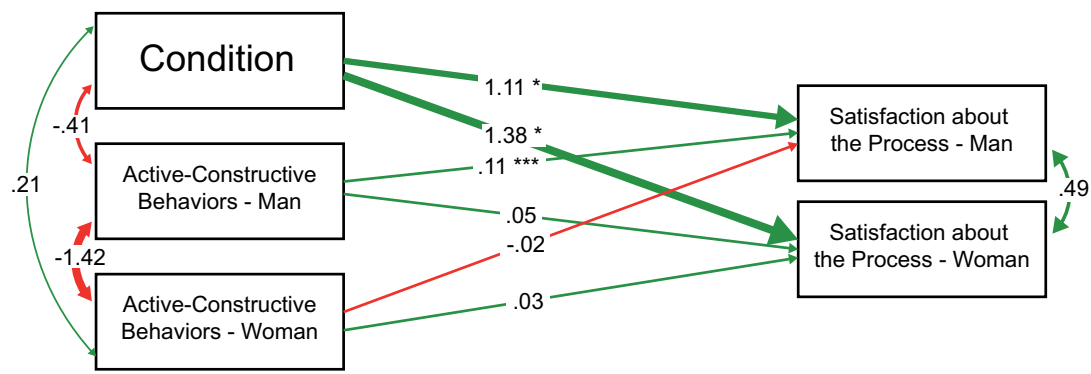

Fig. 3 Full APIM model: Mediation had a significant effect on satisfaction with the process of the discussion for both genders. Higher reports of men on active-constructive conflict behaviours were related to higher reports in their own reports of satisfaction with the process of the discussion. Positive estimates are indicated with green arrows, negative estimates with red arrows. The stronger the effect, the thicker the arrow. The double-headed arrows between "Active-Constructive Man" and "Active-Constructive Woman", "Condition" and "Active-Constructive Man", and "Condition" and "ActiveConstructive Woman" represent the covariance of these pairs of variables. The double-headed arrow between "Satisfaction-Process Woman" and "Satisfaction-Process Man" is the residual non-independence in these outcome scores, which is represented by the covariance between their corresponding two error terms. ${ }^{\star \star *} p<0.001$ and ${ }^{\star} p<0.05$. 
(mediation or control) was included in the model as a betweendyad covariate and treated as a binary variable. There was no actor effect for women $(p=0.5)$, but there was a significant positive effect for men's active-constructive conflict behaviours on men's satisfaction with the process of the discussion, with a value of $0.106(p<0.001,95 \%$ CI $[0.06,0.15])$. The overall actor effect was equal to 0.068 and was statistically significant $(p=0.007,95 \%$ CI $[0.02,0.12])$. No partner effect was found (all $p \geq 0.26$ )

Regarding the effect of condition on satisfaction with the contents of the discussion, women in the mediation condition had on average a value on satisfaction with the contents of the discussion that was 1.38 points higher than that of women in the control condition and this difference was statistically significant $(p=0.031)$. Men in the mediation condition had on average a value on satisfaction with the contents of the discussion that was 1.11 points higher than that of men in the control condition. This difference was also statistically significant $(p=0.004)$.

To test whether in the mediation condition the different satisfaction outcome variables (satisfaction of the couple members about the contents of the discussion, satisfaction of the couple members about the process of the discussion, satisfaction of the mediator about the contents of the discussion, satisfaction of the mediator about the process of the discussion) were interrelated, we conducted Spearman correlations because all of these variables were not normally distributed. We found a strong positive correlation between satisfaction of the couple members with the contents of the discussion and satisfaction of the couple members with the process of the discussion, $\left(r_{\mathrm{s}}=0.74\right.$, $p<0.001)$, as well as between satisfaction of the mediator with the contents of the discussion and satisfaction of the mediator with the process of the discussion $\left(r_{\mathrm{s}}=0.65, p<0.001\right)$. However, there were no significant correlations between satisfaction of the couple members with the contents or process of the discussion, on the one hand, and satisfaction of the mediator with the contents or process of the discussion on the other hand (all $r_{\mathrm{s}} \leq 0.19$ and $p \geq$ 0.26 ). We also conducted Spearman correlations to test whether the mediators' satisfaction with the contents or process of the discussion were related to any other outcome variable, i.e., change in positive affect, change in negative affect, and the IOS after the discussion. We found a positive relation between satisfaction of the mediator with the contents or process of the discussion on the one hand, and change in negative affect, on the other $\left(r_{\mathrm{s}}=0.4\right.$, $p=0.013$ and $r_{\mathrm{s}}=0.35, p=0.033$, respectively). This means that mediators reported more satisfaction with the contents and process in couples who reported a greater increase in negative emotions. Removing the five outliers from the change in negative affect did not change the results. This exploratory result should be informed by future research, as it raises the question of the role that negative emotions play in conflicts (i.e., is it good to openly address and thus increase negative emotions, or should they be reduced?).

To test the impact of mediation and the Dyadic Adjustment Scale score on the level of disagreement at the end of the discussion, we used the APIM to examine the effect of one couple member's Dyadic Adjustment Scale score on their own reports of level of disagreement at the end of the discussion (i.e., the actor effect) and on the partner's level of disagreement at the end of the discussion (i.e., the partner effect) (see Supplementary Fig. 2). Condition (mediation or control) was included in the model as a between-dyad covariate and treated as a binary variable. No actor effect was found (all $p \geq 0.258$ ). We found a negative effect for women's Dyadic Adjustment Scale scores on men's level of disagreement at the end of the discussion, with a value of -0.057 $(p=0.022,95 \%$ CI $[-0.11,-0.01])$, which means that the better the quality of the relationship reported by the women, the lower the level of disagreement reported by the men at the end of the discussion. We did not find any men-to-women partner effect. The overall partner effect was equal to -0.040 and was statistically significant $(p=0.014,95 \%$ CI $[-0.07,-0.01])$. No effect of condition on the level of disagreement at the end of the discussion was detected for women or men (all $p \geq 0.22$ ).

Synchronicity of skin conductance response. Previous studies (Levenson and Gottman, 1983, 1985) have shown a negative correlation between the average score of two questionnaire-based measures of the general level of marital satisfaction (Locke and Wallace, 1959; Burgess et al., 1971) (i.e., unrelated to a conflict discussion) and a physiological linkage index that combines skin conductance level, heart rate, pulse transmission time to the finger, and general somatic activity (an electromechanical transducer attached to the platform under each subject's chair detected its movements) measured during a 15 -min discussion between the couple members on a topic of recurring conflict (Levenson and Gottman, 1983). In our study, we thus assessed whether synchronicity of the electrodermal response (EDR, the index of physiological linkage available in the current experiment) was related to the Dyadic Adjustment Scale score, which measures the quality of the relationship by using four subscales (Dyadic Consensus, Dyadic Satisfaction, Dyadic Cohesion, and Affectional Expression). Since the Pearson correlation of EDR and correlation between the change in slopes of EDR were not normally distributed, we conducted Spearman correlations. In contrast to previous work, a Spearman correlation of the data in the present study revealed a positive relation between the correlation between the change in slopes of EDR and the Dyadic Adjustment Scale $\left(r_{\mathrm{s}}=0.26, p=0.022\right)$. Similarly, a Spearman correlation revealed a positive relation between the Pearson correlation of EDR and the Dyadic Satisfaction subscale only $\left(r_{\mathrm{s}}=0.27, p<0.001\right.$, all other $p \geq 0.3$ ). Moreover, we found a positive relation between the Pearson correlation of EDR and the closeness of the couple members, as measured by the IOS before the discussion $\left(r_{\mathrm{s}}=0.28, p=0.015\right)$ and a trend for a positive relation with the IOS after the discussion $\left(r_{\mathrm{s}}=0.22, p=0.053\right)$. Removing the outliers from the IOS before and after the discussion did not change the results. We did not find any correlation between the correlation between the change in slopes of EDR and the Dyadic Adjustment Scale or the IOS after the discussion (all $r_{s} \leq 0.15$, $p \geq 0.18$ )

As mentioned earlier, other studies (Chanel et al., 2013; Slovák et al., 2014) showed that electrodermal activity synchrony (quantified by Pearson correlations) between participants who had no relationship prior to the experiment was predictive of good collaborative behaviours and that electrodermal activity synchrony (quantified by Pearson correlations between the change in slopes) during a discussion of choice between friends was positively correlated to emotional engagement behaviours, as observed from video recordings. However, another study showed that a physiological linkage index was not correlated with the selfrating of affect of participants during a video-recall session (Levenson and Gottman, 1983). In our study, we found a tendency for a negative relation between the Pearson correlation of EDR and the change in positive affect $\left(r_{\mathrm{s}}=-0.22, p=0.059\right)$, suggesting that the higher the physiological linkage, the lower the increase in positive affect, but no relation between the correlation between the change in slopes of EDR of the electrodermal responses and the change in positive affect $\left(r_{\mathrm{s}}=0.05, p=0.66\right)$. Regarding the collaborative behaviours, no correlation was found between the correlation between the change in slopes of EDR or between the Pearson correlation of EDR and the active-constructive, passive-constructive, active-destructive, or passive-destructive 
conflict behaviours scores (all $r_{\mathrm{s}} \leq 0.10$, all $p \geq 0.25$ ). We also found no correlation between the correlation between the change in slopes of the electrodermal responses or between the Pearson correlation of EDR and the outcome variables change in negative affect, satisfaction with the contents of the discussion, satisfaction with the process of the discussion, and level of disagreement at the end of the discussion (all $r_{s} \leq 0.19$, all $p \geq 0.1$ ).

As the present data suggest that electrodermal synchronicity is related to more satisfaction and closeness in romantic relationships, we also tested whether mediation as opposed to the control condition had an impact on electrodermal activity synchrony between participants. We conducted a MANOVA with condition (mediation or control) as a between-subject variable and the Pearson correlation and correlation between the change in slopes as dependent variables. There was no significant effect of condition on physiological synchrony $(V=0.05, F(2,73)=1.98$, $p=0.15)$.

\section{Discussion}

Mediation helps to reduce couple conflict. To test the causal impact of mediation on conflicts in romantic couples, we conducted a study in which 38 couples were randomly assigned to discuss a topic of recurrent disagreement, either with or without the assistance of a mediator and always in the presence of a silent third party. The present results show that in a conflict discussion in romantic couples, mediation, but not simple negotiation, increased satisfaction with the contents and process of the discussion. Moreover, there were more agreements in mediated couple conflicts than in non-mediated couple conflicts (36 participants declared that they had reached an agreement in the mediation condition, whereas 26 of 36 participants did so in the control condition). Furthermore, compared with negotiation, mediation tended to decrease negative affect and increase positive affect. By showing for the first time the causal effects of mediation on couple conflict, the present results extend previous research and validate mediation as an important tool for resolving disputes. More specifically, we tested the impact of mediation in a real conflict rather than as a staged conflict (Jameson et al., 2009), with a longer duration of the interactions than in previously existing research (Levenson and Gottman, 1985; Driver and Gottman, 2004; Slovák et al., 2014). We also randomly assigned romantic couples to mediation, whereas previous studies used non-random assignments (Jameson et al., 2009), and compared mediation to direct negotiation, as opposed to comparing it to litigation (Shaw, 2014) or arbitration (Brett and Barsness, 1996; Barough et al., 2013).

Firstly, the most interesting result of our study concerns the significant and positive impact of mediation on satisfaction with the contents and process of the discussion. Combined with the tendency of mediation to increase positive affect and decrease negative affect, this result shows that the use of mediation improves the quality of the discussion between couple members, which makes mediation an appealing and emotionally rewarding conflict resolution process for potential parties, regardless of the outcome. It may be interesting to further study whether this impact on satisfaction can create a virtuous circle: if a person is more satisfied about what they discussed and how they discussed it during a mediation session, will they be more eager to have additional sessions or to use mediation again in another situation? Secondly, the positive actor effect of activeconstructive conflict behaviours on satisfaction with the contents and process of the discussion and the tendency of a positive partner effect of active-constructive conflict behaviours on satisfaction with the contents show that couple members who are able to display these behaviours will have a discussion of better quality and may influence each other positively. This effect is reinforced by the fact that the tendency to use activedestructive conflict behaviours such as expressing anger and retaliating is not independent between couple members, which suggests that couple members who adopt such behaviours influence each other negatively. Given the beneficial impact of active-constructive conflict behaviours and the negative impact of active-destructive conflict behaviours, it may be worthwhile to test whether these active-constructive conflict behaviours can be taught in intervention studies.

Regarding the impact of mediation on the perception of closeness between couple members as measured by the IOS, the results of our study are not conclusive but may suggest that mediation could improve interpersonal closeness. Further research is needed to validate this hypothesis.

Regarding the last outcome variable, the level of disagreement at the end of the discussion, we also found no effect of mediation. Further studies are needed to better understand this absence of effect in comparison with the other outcome variables.

Emotional competence is related to higher relationship quality and mindfulness is related to more active-constructive and passive-constructive conflict behaviours. In addition, the present study revealed that the self-reported EI, measured by the total Profile of Emotional Competence score (Brasseur et al., 2013), was positively related to relationship quality as measured by the total Dyadic Adjustment Scale score. This confirms previous research, which showed that participants with higher EI scores had higher scores of close and affectionate relationships (Schutte et al., 2001). However, we found that, contrary to previous results (Barnes et al., 2007; Wachs and Cordova, 2007; Forster, 2017) the total Dyadic Adjustment Scale score was not correlated with the total mindfulness score. This discrepancy might be related to the use of a different measure of mindfulness, namely the Mindful Attention Awareness Scale (Brown and Ryan, 2003), in previous studies (Barnes et al., 2007; Wachs and Cordova, 2007; Forster, 2017). Further studies are needed to better understand the relation between mindfulness and the Dyadic Adjustment Scale score.

We also found that the higher the dispositional mindfulness, the higher the preference to use active-constructive conflict behaviours (perspective-taking, creating options, expressing emotions) and passive-constructive conflict behaviours (reflective thinking, delay responding, and adapting). This is consistent with a previous study that showed that higher levels of self-compassion are correlated with an attitude of compromise in conflict situations (Yarnell and Neff, 2013). It will be interesting in future studies to further investigate the relationships identified between EI and the quality of the couple relationship on one the hand, and mindfulness and conflict behaviours on the other.

Synchrony in electrodermal activity is related to closeness and change in positive affect. For the two electrodermal activity synchrony indices, we could not identify any impact of mediation. However, we could identify a positive relation between one of our two physiological indices, the Pearson correlation of EDR, and the IOS before the discussion. We also found a tendency for a positive relation between the same Pearson correlation of EDR and the IOS after the discussion. We did not find any relation between our second index, the correlation between the change in slopes of EDR and the IOS before or after the discussion. In further research, it would be interesting to explore what might influence this relation positively or negatively. We could also identify a tendency for a negative relation between the Pearson correlation of EDR and change in positive affect. A previous study 
about the relation between the physiological linkage of couple members and its affect in the context of a conflictual discussion (Levenson and Gottman, 1983) showed that the physiological linkage of couple members was not correlated to the continuous self-rating of affect by participants during video recall. The selfrating was done during the recall by moving a dial between 0 , meaning "very negative", to 9 , meaning "very positive". However, such self-rating of affect is not similar to the change between the pre-test and post-test self-rating of affect that we used. Further research should be conducted to better understand the relationship between physiological linkage and the closeness of the couple members on the one hand, and positive affect on the other. In particular, it could be interesting to extend our methods and, as done previously (Levenson and Gottman, 1983), study the relationship between continuous self-rating of video recall and physiological indices.

We found that the correlation between the change in slopes of $E D R$ was positively related to the total score on the Dyadic Adjustment Scale and that the Pearson correlation was also positively related to the Dyadic Satisfaction subscale. These results are inconsistent with data obtained in previous research (Levenson and Gottman, 1983), which showed that the physiological linkage of couple members was negatively related to marital satisfaction. Our data support the view that physiological linkage is a sign of a positive and constructive social interaction in general (Chanel et al., 2013; Slovák et al., 2014), as physiological linkage was related to more interpersonal closeness before the conflict and had a tendency to also be related to more interpersonal closeness after the conflict. There were no differences in electrodermal activity synchrony between the mediated and non-mediated condition. Furthermore, there were no overall effects of conflict on electrodermal activity synchrony. The present data thus suggest that electrodermal activity synchrony may not be the best biological marker of arousal states in couple conflicts. Notably, our study used electrodermal activity only to identify the level of physiological linkage, whereas previous studies also included the synchrony of the heartbeat or of facial expressions (Levenson and Gottman, 1983; Slovák et al., 2014). In future studies, a worthwhile endeavour may be to include not only heartbeat or facial expressions in the calculation of physiological linkage indices, but also brain responses to seeing one's romantic partner (Rafi et al., 2020). It may also be useful to apply other methods presented in recent studies, such as non-linear models or temporal interpersonal emotion systems (Guastello et al., 2006 and Butler, 2011, respectively). Examining the effect of empathy could be of value, since several studies (Levenson and Ruef, 1992; Guastello et al., 2006; Marci et al., 2007; Soto and Levenson, 2009) have shown that physiological linkage is related to higher empathy. Moreover, it may be interesting to study the influence of stress levels of couple members by measuring cortisol levels (Ditzen et al., 2009, 2011, 2012; Saxbe and Repetti, 2010; Laurent et al., 2013). Notably, in our study, the average duration of the discussions in both conditions was significantly longer than that in previous research (Levenson and Gottman, 1983) (around 50 min compared with $15 \mathrm{~min}$ ), which could explain the difference in physiological linkage results between our results and those from previous research (Levenson and Gottman, 1983). Furthermore, our findings may be limited by artefacts because of the movements of the participants and the fact that we calculated indices of physiological linkage on a complete discussion, whereas it is possible that some linkage may exist during highly empathic phases of the discussion and not during others.

Mediation is an efficient tool for dispute resolution. By showing the benefits of mediation on couple conflicts in a randomized controlled trial, the present results suggest that the use of mediation should be reinforced as a form of cost-efficient dispute management. In other words, the present findings can increase the incentive for policy makers, judges, legal systems, and parties in conflict to support or engage in mediation. Future work is needed to establish which forms of dispute resolution (e.g., couple therapy, counselling (Gottman, 1999), conflict coaching (Brinkert, 2016), self-distancing training (Kross and Ayduk, 2008), third-party perspective training (Finkel et al., 2013), or compassion training (Klimecki, 2019)) are most efficient in particular conflict settings (e.g., interpersonal or intergroup conflicts, phases of low or high conflict; Klimecki, 2019).

Helping users make better informed decisions when choosing a form of dispute resolution. Beyond showing the beneficial impact of mediation on couple conflict, our results further suggest that a protocol can be used to compare the effectiveness of various forms of dispute resolution by measuring the following five variables: (i) agreements obtained on the topic of discussion, (ii) satisfaction with the contents of the discussion and satisfaction with the process of the discussion, (iii) level of disagreement at the end of the discussion, (iv) change in positive affect and change in negative affect, and (v) IOS after the discussion. Extending the use of such a protocol could contribute to the emergence of scientifically valid standards of practice that would help users make more informed decisions when choosing the form of dispute prevention or resolution intervention that is best suited to their situation, e.g., the nature and degree of their conflict and their personality traits. These forms of dispute prevention or intervention could include, beyond simple negotiation or legal proceedings, mediation, as well as self-distancing training (Kross and Ayduk, 2008), third-party perspective training (Finkel et al., 2013), compassion training (Klimecki, 2019), therapy or counselling (Gottman, 1999), or conflict coaching (Brinkert, 2016).

Limitations and ideas for future study. Although this study shows the beneficial effect of mediation on couple conflict and thus has important implications for conflict resolution, it also has some limitations. For the control condition, we chose to have a silent-third party in the room, in order to test as conservatively as possible whether the mere presence of another person made a difference or whether it was actually the intervention of the mediator per se. In addition, our aim was to provide couples with an environment where a trained mediator could intervene, should the conflict get too heated. This happened in one case, where the silent mediator had to stop the discussion and proceed with a mediation. Furthermore, couples in the control condition were provided with instructions that may have helped them to have a more effective conversation. Although our control condition thus does not represent couples' discussions as they most likely happen at home, our conditions allow to test the impact of a mediator in a very rigorous and conservative way that controls for the presence of a third party and for the instructions given to structure the session. The instructions in the control condition were given to participants and were minimal in order to keep the conversation as natural as possible (see Supplementary Note 1). The instructions in the mediation condition were given to the mediator (see Supplementary Note 2).

On average, the mediated discussions were probably not sufficiently long for the mediation to be transformative (Folger and Bush, 1996) and to have more impact on the level of disagreement at the end of the discussion and on the IOS. In practice, it is common to resolve couple conflicts in several mediation sessions (Folger and Bush, 1996) and to openly discuss emotions during these sessions to achieve a sustainable resolution 
of the conflict at hand, which we did not specifically instruct our participants to do in either of the two conditions (Folger and Bush, 1996; Bodtker and Jameson, 2001; Jameson et al. 2009). In future research, it will be interesting to study longer interventions over multiple sessions and to examine in more detail the psychological mechanisms of mediation. More specifically, future studies that investigate the dynamic interplay between emotional expressions, body language, and a mediator's speech and the involved parties could explore which interventions of a mediator are most beneficial for promoting conflict resolution. Moreover, it may be of interest to test the psychological mechanisms (such as self-distancing, emotion regulation, perspective taking, changes in social emotions) through which the beneficial impact of mediation is achieved, as well as the impact of the different styles of mediation (facilitative, evaluative, transformative), the impact of longer mediations, and the situations in which different types of conflict interventions work best (e.g., Klimecki, 2019). One of the most important questions for future research will be to test the impact of mediation in couples with very high levels of conflict. Another promising avenue would be to study how training that is focused on developing the ability to use activeconstructive and passive-constructive conflict behaviours could influence the outcomes of conflict resolution sessions, as measured with the outcome variables used in our research. We did not find any correlation between satisfaction with the contents and the process of the couple members, and satisfaction with the contents and the process of the mediators; further study is needed to understand this absence of correlation.

Mediation tended to increase positive affect and decrease negative affect of the couple members. Further analysis of the audio and video recordings of the discussions could investigate how the mediators' behaviors influence the dynamics of the discussion. Further longitudinal research could also show whether this tendency to improve positive and negative affect is sustainable and whether it positively conditions the couple members to have less conflictual discussions in the hours or days following the mediation session.

Further longitudinal research could also test how long the impact of mediation on the existence of an agreement at the end of the discussion (measured by "yes" or "no") lasts and whether a follow-up mediation session could further improve the perception of an agreement.

Considering that there was an actor and partner effect of active-constructive conflict behaviours on satisfaction with the contents of the discussion, a valuable approach may be to test whether people who have been trained, prior to a mediation session, to use constructive behaviours when discussing difficult topics, such as perspective-taking and expressing emotions, achieve better outcomes than a control group does and how those people mutually influence each other depending on the behaviour that they display.

More research is needed to evaluate the impact of mediation on psychological linkage and whether and how this linkage can inform the parties in mediation, and the mediator, about the progress of the discussion towards a positively viewed outcome. Additional research is also needed to evaluate the impact of different styles and forms of mediation interventions (e.g., facilitative as opposed to transformative), as well as the impact of mediation on the five outcome variables at the different phases of a conflict resolution session. Of particular interest will be to further study the relation between the mediator's evaluations and the participants' evaluations, since, for example, the satisfaction of the mediator and that of the participants were not correlated. Furthermore, we found that the higher the increase in negative affect of the parties, the higher the satisfaction of the mediator, which is counterintuitive, but may point to the importance of addressing negative emotions in conflicts.

In addition to the collection of skin conductance data, the discussions of the participants were videotaped. The emotional expressions (face, speech, gestures) from these videos are currently being analysed with automated software and elaborate manual coding by using the specific affect coding system (Coan and Gottman, 2007). This could be extended further by studying how the availability of real-time predictive data about the emotional arousal of the parties might help reach better outcomes. Future studies with randomized assignments to intervention groups and real conflicts should test how far the beneficial effects of mediation and other forms of dispute resolution can be extended to other conflict settings, such as business conflicts, workplace conflicts, intergroup conflicts, and intractable international conflicts by using the protocol of the present study.

\section{Conclusion}

The present data suggest that, compared with negotiation, mediation is a powerful intervention strategy for conflict resolution in romantic couples and has a positive impact on satisfaction with the contents and process of the discussion and the probability of reaching an agreement. Our data also show promising effects of mediation on positive and negative affects. Although this study focused on mediation in romantic couples, its results could also be of interest for disputes in the workplace or business conflicts.

\section{Data availability}

The datasets analysed during the current study are available in the Dataverse repository: https://doi.org/10.7910/DVN/SVXIPH. The data sets generated and/or analysed in the current study are available from the corresponding author (F.B.) on request.

\section{Code availability}

The code generated and/or analysed in the current study are available from the corresponding author (F.B.) on request.

Received: 29 February 2020; Accepted: 15 September 2020; Published online: 21 October 2020

\section{References}

Alferes VR, Kenny DA (2009) SPSS programs for the measurement of nonindependence in standard dyadic designs. Behav Res Methods 41(1):47-54 https://doi.org/10.3758/BRM.41.1.47

Alkoby A et al. (2017) Increased support for political compromise in the Israeli-Palestinian conflict following an 8-week mindfulness workshop. Mindfulness 8(5):1345-1353. https://doi.org/10.1007/s12671-017-0710-5

Aron A, Aron EN, Smollan D (1992) Inclusion of Other in the Self scale and the structure of interpersonal closeness. J Pers Soc Psychol 63:596

Baer RA et al. (2006) Using self-report assessment methods to explore facets of mindfulness. Assessment 13:27-45. https://doi.org/10.1177/1073191105283504

Barnes S et al. (2007) The role of mindfulness in romantic relationship satisfaction and responses to relationship stress. J Marital Fam Ther 33(4):482-500. https://doi.org/10.1111/j.1752-0606.2007.00033.x

Barough AS, Shoubi MV, Preece CN (2013) Evaluating the effectiveness of mediation and arbitration processes in resolving disputes in the Malaysian construction industry. Int J Civ Eng 2(1):21-28

Bloch L, Haase CM, Levenson RW (2014) Emotion regulation predicts marital satisfaction : more than a wives' tale. Emotion 14(1):130-144. https://doi.org/ 10.1037/a0034272

Bodtker AM, Jameson JK (2001) Emotion in conflict formation and its transformation: application to organizational conflict management. Int J Confl Manag 12(3):259-275. https://doi.org/10.1108/eb022858

Brackett MA, Warner RM, Bosco JS (2005) Emotional intelligence and relationship quality among couples. Pers Relatsh 12(2):197-212. https://doi.org/10.1111/ j.1350-4126.2005.00111.x 
Brasseur S et al. (2013) The profile of emotional competence (PEC): development and validation of a self-reported measure that fits dimensions of emotional competence theory. PLoS ONE 8(5):e62635. https://doi.org/10.1371/journal. pone. 0062635

Brett JM, Barsness ZL (1996) The effectiveness of mediation : an independent analysis of cases handled by four major service providers. Negot J 152 (12):259-269. https://doi.org/10.1007/BF02187632

Brinkert R (2011) Conflict coaching training for nurse managers: a case study of a two-hospital health system. J Nurs Manag 19(1):80-91. https://doi.org/ $10.1111 / j .1365-2834.2010 .01133 . x$

Brinkert R (2016) State of knowledge: conflict coaching theory, application, and research. Confl Resolut Q 33(4):383-401. https://doi.org/10.1002/crq.21162

Brown KW, Goodman RJ, Inzlicht M (2012) Dispositional mindfulness and the attenuation of neural responses to emotional stimuli. Soc Cogn Affect Neurosci 8:93-99. https://doi.org/10.1093/scan/nss004

Brown KW, Ryan RM (2003) The benefits of being present: mindfulness and its role in psychological well-being. J Pers Soc Psychol 84(4):822-848. https:// doi.org/10.1037/0022-3514.84.4.822

Burgess EW, Locke HJ, Thomes MM (1971) The family. Van Nostrand Reinhold, New York

Bush RAB, Folger JP (1984) The promise of mediation: the transformative approach to conflict. Jossey-Bass, San Francisco

Butler EA (2011) Temporal interpersonal emotion systems: the 'TIES' that form relationships. Pers Soc Psychol Rev 15(4):367-393. https://doi.org/10.1177/ 1088868311411164

Capobianco S, Davis MH, Kraus LA (2008) Conflict dynamics profile technical guide. Eckerd College, St Petersburg, Florida

Chanel G et al. (2013) Assessment of computer-supported collaborative processes using interpersonal physiological and eye-movement coupling. In 2013 Hum Assoc Conf Affect Comput Intell Interact. IEEE: Geneva, Switzerland 116-122. https://doi.org/10.1109/ACII.2013.26

Charkoudian L (2016) What works in district court day of trial mediation: effectiveness of various mediation strategies on short-and long-term outcomes. Administrative Office of the Courts, Maryland Judiciary, Annapolis

Coan JA, Gottman JM (2007) The specific affect (SPAFF) coding system. Handbook of emotional elicitation assessment. Oxford University Press

Collins English Dictionary (2020) Definition of 'negotiation'. Collins English Dictionary. https://www.collinsdictionary.com/dictionary/english/negotiation. Accessed 13 May 2020

Coontz S (2006) The origins of modern divorce. Fam Process 46:7-16. https://doi. org/10.1002/9781118659991

Crawford JR, Henry JD (2004) The positive and negative affect schedule (PANAS): construct validity, measurement properties and normative data in a large non-clinical sample. Br J Clin Psychol 43(Part 3):245-265. https://doi.org/ $10.1348 / 0144665031752934$

Crowne DP, Marlowe D (1960) A new scale of social desirability independent of psychopathology. J Consult Psychol 24(4):349-354. https://doi.org/10.1037/ h0047358

Davis MH, Capobianco S, Kraus LA (2004) Measuring conflict-related behaviors: reliability and validity evidence regarding the Conflict Dynamics Profile. Educ Psychol Meas 64(4):707-731. https://doi.org/10.1177/0013164404263878

Ditzen B et al. (2009) Intranasal oxytocin increases positive communication and reduces cortisol levels during couple conflict. Biol Psychiatry 65(9):728-731. https://doi.org/10.1016/j.biopsych.2008.10.011

Ditzen B et al. (2011) Assisting couples to develop healthy relationships: effects of couples relationship education on cortisol. Psychoneuroendocrinology 36 (5):597-607. https://doi.org/10.1016/j.psyneuen.2010.07.019

Ditzen B et al. (2012) Sex-specific effects of intranasal oxytocin on autonomic nervous system and emotional responses to couple conflict. Soc Cogn Affect Neurosci. https://doi.org/10.1093/scan/nss083

Driver JL, Gottman JM (2004) Daily marital interactions and positive affect during marital conflict among newlywed couples. Fam Process 43(3):301-315

Dunn RL, Schwebel AI (1995) Meta-analytic review of marital therapy outcome research. J Fam Psychol 9(1):58-68. https://doi.org/10.1037/0893-3200.9.1.58

European Parliament (2011) Quantifying the cost of not using mediation-a data analysis. European Parliament, Brussels, Belgium

Finkel EJ et al. (2013) A brief intervention to promote conflict reappraisal preserves marital quality over time. Psychol Sci 24(8):1595-1601. https://doi.org/ $10.1177 / 0956797612474938$

Folger JP, Bush RAB (1996) Transformative mediation and third-party intervention: ten hallmarks of a transformative approach to practice. Mediat Q 13 (4):263-278. https://doi.org/10.1002/crq.3900130403

Forster PM (2017) Mindfulness and the quality of romantic relationships: is it all about well-being? Open J Soc Sci 5(5):59-63. https://doi.org/10.4236/ jss. 2017.55005

Glasl F (2013) The process of conflict escalation and role of third-parties. In: Bomers GBJ, Peterson RB (eds) Confl Manag Ind Relations. Springer Science \& Business Media, pp. 119-140
Gottman JM (1999) The marriage clinic: a scientifically based marital therapy Norton Professional Books, New York

Gottman JM, Levenson RW (1992) Marital processes predictive of later dissolution: behavior, physiology, and health. J Pers Soc Psychol 63(2):221-233. https:// doi.org/10.1037/0022-3514.63.2.221

Guastello SJ, Pincus D, Gunderson PR (2006) Electrodermal arousal between participants in a conversation: nonlinear dynamics and linkage effects. Nonlinear Dyn Psychol Life Sci 10(3):365-99

Haddad L, Phillips KD, Bone MJ (2016) High-conflict divorce: a review of the literature. Am J Fam Law 29(4):243-258

Halperin E et al. (2013) Can emotion regulation change political attitudes in intractable conflicts? From the laboratory to the field. Psychol Sci. https://doi. org/10.1177/0956797612452572.

Halperin E (2013) Emotion, emotion regulation, and conflict resolution. Emot Rev 6:68-76. https://doi.org/10.1177/1754073913491844

Halperin E (2015) Emotions in conflict: inhibitors and facilitators of peace making. Routledge, Oxford

Halperin E, Gross JJ (2011) Emotion regulation in violent conflict: reappraisal, hope, and support for humanitarian aid to the opponent in wartime. Cogn Emot 25(7):1228-1236. https://doi.org/10.1080/02699931.2010.536081

Hann RG et al. (2001) Evaluation of the Ontario mandatory mediation program final report-the first 23 months. Queen's Printer, Ottawa, Ontario, http:// www.ontla.on.ca/library/repository/mon/1000/10294962.pdf

Hoffman ML (2008) Empathy and prosocial behavior. In: Lewis M, Haviland-Jones JM, Feldman. In: Barrett L (eds) Handbook of Emotions. The Guilford Press, New York, pp. $440-455$

International Mediation Institute (2020a) Styles of mediation. https://www. imimediation.org/resources/background/styles-of-mediation/. Accessed 13 May 2020

International Mediation Institute (2020b) What is mediation? https://www. imimediation.org/resources/background/what-is-mediation/. Accessed 13 May 2020

Jameson JK et al. (2009) Exploring the role of emotion in conflict transformation. Confl Resolut Q 27(2):167-192. https://doi.org/10.1002/crq.254

Jones TS, Bodtker A (1999) Agreement, maintenance, satisfaction and relitigation in mediated and non-mediated custody cases: a research note. J Divorce Remarriage 32(1/2):17. https://doi.org/10.1300/J087v32n01_02

Jones TS, Bodtker A (2001) Mediating with heart in mind: addressing emotion in mediation practice. Negot J 17(3):217-244. https://doi.org/10.1023/ A: 1013283710190

Jordan PJ, Troth AC (2002) Emotional intelligence and conflict resolution: implications for human resource development. Adv Dev Hum Resour 4 (1):62-79. https://doi.org/10.1177/1523422302004001005

Kabat-Zinn J (2009) Wherever you go, there you are: mindfulness meditation in everyday life. Hachette Books, New York, 10.1016/0005-7967(95)90133-7

Kaiser P, Gabler AM (2014) Prozessqualität und langzeit effekte in der mediation. Zeitschrift für Konfliktmanagement 6:180-184

Katz E (2007) A family therapy perspective on mediation. Fam Process 46 (1):93-107. https://doi.org/10.1111/j.1545-5300.2006.00194.x

Kenny DA, Kashy DA, Cook WL (2006) Dyadic data analysis. The Guilford Press, New York

Killman RH, Thomas KW (1977) Thomas-Kilmann conflict mode instrument. Xicom: Sterling Forest, New York

Van Kleef G, De Dreu C, Manstead A (2006) Supplication and appeasement in conflict and negotiation: the interpersonal effects of disappointment, worry guilt, and regret. J Pers Soc Psychol 91(1):124-142. https://doi.org/10.1037/ 0022-3514.91.1.124

Van Kleef G, De Dreu CKW, Manstead ASR (2004) The interpersonal effects of emotions in negotiations: a motivated information processing approach. J Pers Soc Psychol 87(4):510-528. https://doi.org/10.1037/0022-3514.87.4.510

Van Kleef GA, Côté S (2007) Expressing anger in conflict: when it helps and when it hurts. J Appl Psychol 92(6):1557-1569. https://doi.org/10.1037/00219010.92.6.1557

Klimecki OM (2015) The plasticity of social emotions. Soc Neurosci 10:466-473. https://doi.org/10.1080/17470919.2015.1087427

Klimecki OM (2019) The role of empathy and compassion in conflict resolution. Emot Rev 11(4):1-16. https://doi.org/10.1177/1754073919838609

Kross E, Ayduk O (2008) Facilitating adaptive emotional analysis: distinguishing distanced-analysis of depressive experiences from immersed-analysis and distraction. Pers Soc Psychol Bull 34(7):924. https://doi.org/10.1177/ 0146167208315938

Laurent $\mathrm{H}$ et al. (2013) Sex-specific effects of mindfulness on romantic partners' cortisol responses to conflict and relations with psychological adjustment Psychoneuroendocrinology 38(12):2905-2913. https://doi.org/10.1016/j psyneuen.2013.07.018

Lebow JL et al. (2012) Research on the treatment of couple distress. J Marital Fam Ther 38(1):145-168. https://doi.org/10.1111/j.1752-0606.2011.00249.x 
Lelieveld G-J et al. (2012) Why anger and disappointment affect other's bargaining behavior differently: the moderating role of power and the mediating role of reciprocal and complementary emotions. Personal Soc Psychol Bull 38 (9):1209-1221. https://doi.org/10.1177/0146167212446938

Levenson RW, Gottman JM (1983) Marital interaction: physiological linkage and affective exchange. J Pers Soc Psychol 45(3):587-597. https://doi.org/10.1037/ 0022-3514.45.3.587

Levenson RW, Gottman JM (1985) Physiological and affective predictors of change in relationship satisfaction. J Pers Soc Psychol 49:85-94. https://doi.org/ 10.1037/0022-3514.49.1.85

Levenson RW, Ruef AM (1992) Empathy: a physiological substrate. J Pers Soc Psychol 63(2):234-246. https://doi.org/10.1037/0022-3514.63.2.234

Locke HJ, Wallace KM (1959) Short marital-adjustment and prediction tests: their reliability and validity. Marriage Fam Living 21(3):251-255. https://doi.org/ $10.2307 / 348022$

Marci CD et al. (2007) Physiologic correlates of perceived therapist empathy and social-emotional process during psychotherapy. J Nerv Ment Dis 195 (2):103-111. https://doi.org/10.1097/01.nmd.0000253731.71025.fc

Marriage and divorce statistics (2019) Eurostat. http://ec.europa.eu/eurostat/ statistics-explained/index.php/Marriage_and_divorce_statistics. Accessed 17 May 2020

Mueller JS, Curhan JR (2006) Emotional intelligence and counterpart mood induction in a negotiation. Int J Confl Manag 17(2):110-128. https://doi.org/ $10.1108 / 10444060610736602$

Nair N (2008) Towards understanding the role of emotions in conflict: a review and future directions. Int J Confl Manag 19(4):359-381. https://doi.org/ $10.1108 / 10444060810909301$

Pietroni D et al. (2008) Emotions as strategic information: effects of other's emotional expressions on fixed-pie perception, demands, and integrative behavior in negotiation. J Exp Soc Psychol 44(6):1444-1454. https://doi.org/ 10.1016/j.jesp.2008.06.007

Pruitt DG (1998) Social conflict. In: Gilbert DT, Fiske ST, Lindzey G (eds) Handbook of social psychology, 4th edn. McGraw Hill, New York, pp. 470-503

Rafi $\mathrm{H}$ et al. (2020) Impact of couple conflict and mediation on how romantic partners are seen. Cortex 130:302-317. https://doi.org/10.1016/j. cortex.2020.04.036

Retzinger S, Scheff T (2000) Emotion, alienation and narratives: resolving intractable conflict. Mediat Q 18:71-85

Riskin LI (2005) Replacing the mediator orientation grids, again: the new new grid system. Altern High Cost Litig 23(8):127-132

Salovey P, Mayer JD (1990) Emotional intelligence and its relationship to other intelligences. Imagin Cogn Pers 9(3):185-211. https://doi.org/10.1037/00223514.50.2.421

Saxbe D, Repetti RL (2010) For better or worse? Coregulation of couples' cortisol levels and mood states. J Pers Soc Psychol 98(1):92-103. https://doi.org/ $10.1037 / \mathrm{a} 0016959$

Schutte NS et al. (2001) Emotional intelligence and interpersonal relations. J Soc Psychol 141(4):523-536

Shaw LA (2014) Divorce mediation outcome research: a meta-analysis. Confl Resolut Q 27(4):447-467. https://doi.org/10.1002/crq

Slovák P et al. (2014) Exploring skin conductance synchronisation in everyday interactions. In Proc 8th Nord Conf Human-Computer Interact Fun, Fast, Found. ACM 511-520. https://doi.org/10.1145/2639189.2639206

Smith L, Heaven PCL, Ciarrochi J (2008) Trait emotional intelligence, conflict communication patterns, and relationship satisfaction. Pers Individ Dif 44 (6):1314-1325. https://doi.org/10.1016/j.paid.2007.11.024

Soto JA, Levenson RW (2009) Emotion recognition across cultures: the influence of ethnicity on empathic accuracy and physiological linkage. Emotion 9 (6):874-884. https://doi.org/10.1037/a0017399

Sourdin T (2020) Mediation. In: Alternative dispute resolution, 6th edn. ThomsonReuters, Sydney, pp. 77-120

Spanier GB (1976) Measuring dyadic adjustment: new scales for assessing the quality of marriage and similar dyads. J Marriage Fam 38(1):15-28. https:// doi.org/10.2307/350547

Stanley SM et al. (2001) Marriage in Oklahoma. Oklahoma State University, Stillwater, Oklahoma

Stas L et al. (2018) Giving dyadic data analysis away: a user-friendly app for actor-partner interdependence models. Pers Relatsh 25(1):103-119. https:// doi.org/10.1111/pere.12230
Swaab R, Brett JM (2012) Managing emotions in employment disputes. INSEAD, Kellogg School of Management, Fontainebleau, France

Umberson D et al. (2006) You make me sick: marital quality and health over the life course. J Health Soc Behav 47(1):1-16. https://doi.org/10.1177/ 002214650604700101

Victorian Civil and Administrative Tribunal, Annual Report 2017-2018 (2018).

Wachs K, Cordova JV (2007) Mindful relating: exploring mindfulness and emotion repertoires in intimate relationships. J Marital Fam Ther 33(4):464-481. https://doi.org/10.1111/j.1752-0606.2007.00032.x

Williams K (2003) Has the future of marriage arrived? A contemporary examination of gender, marriage, and psychological well-being. J Health Soc Behav 44(4):470-487. https://doi.org/10.2307/1519794

Wissler RL (2017) Resolution report of the task force on research on mediator techniques. American Bar Association. https://www.americanbar.org/ content/dam/aba/administrative/dispute_resolution/ med_techniques_tf_report.authcheckdam.pdf.

Yarnell LM, Neff KD (2013) Self-compassion, interpersonal conflict resolutions, and well-being. Self Identity 12(2):146-149. https://doi.org/10.1080/ 15298868.2011 .649545

\section{Acknowledgements}

We thank Aleksander Sobolewski and his team from the Psychophysiology Facility at Campus Biotech as well as Remi Neveu from the Brain and Behaviour Laboratory for setting up the lab rooms, Theodoros Kostoulas and Guillaume Chanel for their mentoring, Halima Rafi for conducting some of the experiments, the Eckerd College (St. Petersburg, Florida, USA) for the availability of the free licenses of the Conflict Dynamics Profile and all the mediators who participated pro bono to the experiments (by alphabetical order): Viktoria Aversano, Christophe Imhoos, Jeremy Lack, Alexis Lafranchi, Isabelle Laugier, Fernanda Salina, and Birgit Sambeth Glasner. We also thank Jeremy Lack for his help in setting up the panel of mediators and commenting on a previous version of the present paper.

\section{Author contributions}

F.B., O.M.K., and T.P. conceived the experiment, F.B. conducted the experiment, F.B. analysed the results under the supervision of O.M.K., F.B. and O.M.K. wrote the manuscript. All authors reviewed and approved the final version of the manuscript.

\section{Competing interests}

The authors declare no competing interests.

\section{Additional information}

Supplementary information is available for this paper at https://doi.org/10.1057/s41599 020-00622-8.

Correspondence and requests for materials should be addressed to F.B.; or O.M.K.

Reprints and permission information is available at http://www.nature.com/reprints

Publisher's note Springer Nature remains neutral with regard to jurisdictional claims in published maps and institutional affiliations.

Open Access This article is licensed under a Creative Commons Attribution 4.0 International License, which permits use, sharing, adaptation, distribution and reproduction in any medium or format, as long as you give appropriate credit to the original author(s) and the source, provide a link to the Creative Commons license, and indicate if changes were made. The images or other third party material in this article are included in the article's Creative Commons license, unless indicated otherwise in a credit line to the material. If material is not included in the article's Creative Commons license and your intended use is not permitted by statutory regulation or exceeds the permitted use, you will need to obtain permission directly from the copyright holder. To view a copy of this license, visit http://creativecommons.org/ licenses/by/4.0/.

(C) The Author(s) 2020 